\title{
Circulating miR-200a is a novel molecular biomarker for early-stage renal cell carcinoma
}

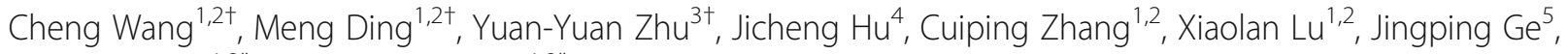
Jun-Jun Wang ${ }^{1,2^{*}}$ and Chunni Zhang ${ }^{1,2^{*}}$

\begin{abstract}
Background: Circulating microRNAs (miRNAs) have been recognized as novel molecular markers for renal cell carcinoma (RCC) diagnosis. However, the clinical impact of circulating miRNA has rarely been evaluated for the early detection of RCC. Moreover, miRNAs also play important roles in regulating RCC tumorigenesis. The aim of this study is to assess the serum signatures of the epithelial-mesenchymal transition (EMT)-related miRNA-200 family in RCC patients and evaluate their diagnostic usefulness for early-stage RCC, and further explore the functions of specifically altered miRNAs that regulate pathological genes during the RCC tumorigenesis.

Methods: The serum levels of three miR-200 miRNAs (miR-200a, miR-200b and miR-200c) were firstly measured in 26 RCC patients and 26 noncancer controls of the training phase using quantitative real-time polymerase chain reaction (RT-qPCR). Markedly dysregulated miRNAs in RCC patients were subsequently verified by RT-qPCR in an independent validation phase that consist of 73 patients and 73 controls. Differentially expressed miRNAs were further examined in RCC urine samples and corresponding controls. Additionally, the mechanisms underlying the altered miRNAs involved in RCC tumorigenesis were also elucidated.
\end{abstract}

Results: Of the three examined miRNAs, only miR-200a showed consistently decreased levels in serum of the RCC patients, especially in those with stage I disease, as compared with controls $(P<0.001)$. MiR-200a is also frequently downregulated in RCC urine samples. Mechanistic investigations revealed that E2F3, an oncogene with strong proliferative and cell cycle regulation potential, is a direct target gene of miR-200a in RCC. E2F3 protein levels in RCC tissues and cell lines were increased and inversely associated with miR-200a levels. Upregulation of miR-200a decreased the expression of E2F3, with consequent repressed RCC cell proliferation and induced cell cycle arrest at G0/G1 phase in vitro. In contrast, inhibition of miR-200a in RCC cells resulted in increased expression of E2F3 and enhanced cell proliferation, and promoted G1/S transition.

Conclusions: Serum miR-200a has the potential to be served as a novel noninvasive auxiliary diagnostic biomarker for the early detection of RCC, and the identified novel molecular interaction between miR-200a and E2F3 may provide insights into novel therapies for RCC.

Keywords: microRNA, Serum, miR-200a, Renal cell carcinoma, Early diagnosis, E2F3

\footnotetext{
* Correspondence: wangjunjun9202@163.com; zchunni27@hotmail.com

${ }^{+}$Cheng Wang, Meng Ding and Yuan-Yuan Zhu contributed equally to this work.

${ }^{1}$ Department of Clinical Laboratory, Jinling Hospital, State Key Laboratory of Analytical Chemistry for Life Science, Nanjing University School of Medicine, 305 East Zhongshan Road, Nanjing 210002, China

Full list of author information is available at the end of the article
}

(c) The Author(s). 2019 Open Access This article is distributed under the terms of the Creative Commons Attribution 4.0 International License (http://creativecommons.org/licenses/by/4.0/), which permits unrestricted use, distribution, and reproduction in any medium, provided you give appropriate credit to the original author(s) and the source, provide a link to the Creative Commons license, and indicate if changes were made. The Creative Commons Public Domain Dedication waiver (http://creativecommons.org/publicdomain/zero/1.0/) applies to the data made available in this article, unless otherwise stated. 


\section{Introduction}

Renal cell carcinoma (RCC) is the most common and lethal genitourinary malignancy in both men and women, which accounts for approximately 425,000 new cancer cases and 177,000 deaths in 2015 worldwide [1]. Recent epidemiologic survey has revealed that the incidence of $\mathrm{RCC}$ has been steadily rising by $2 \sim 4 \%$ each year and its mortality rate has reached $40 \%$ [2]. Nowadays, RCC is increasingly recognized as a heterogeneous disease, and clear cell RCC (ccRCC) comprise the main histological category and the most aggressive form of RCC, however, the etiology and molecular basis of most ccRCC remains unclear [3]. RCC is generally resistant to chemotherapy and radiation therapy, and surgical resection remains the most effective treatment for localized RCC tumors. Numerous studies have demonstrated that early diagnosis of asymptomatic small renal tumors leads to better treatment results, for instance, it is reported that the 5-year survival of RCC is estimated to be approximately $55 \%$ and that of metastatic RCC is only $10 \%$ [4]. However, patients with RCC are often identified by chance during routine imaging for many other comorbidities, and only $30 \%$ of patients are diagnosed on the basis of symptoms [5]. Even worse, at diagnosis, around 30\% of the patients have metastasis disease and even a higher percentage of patients develop metachronous metastases after nephrectomy $[2,6]$. Currently, the routine physical examination is insufficient for diagnosing of small renal tumors, and several radiological techniques such as abdominal ultrasound scanning, computed tomography and magnetic resonance imaging which were frequently used in clinical may allow to detect small asymptomatic tumors, nevertheless, those imaging approach are quite expensive and the limitations in specificity and accuracy make it may not always accurately discriminate the benign renal tumor formation from the malignant one [5]. On the other hand, renal biopsy is an invasive method of investigation associated with certain complications and has been limited by concerns about accuracy and safety [7]. So far, no accurate biomarker for RCC currently available. Despite the findings of routine diagnostic blood tests might be altered by RCC, but no change is pathognomonic. In addition, although several serum proteins have been ported to be able to detect the presence of advanced or recurrent RCC, unfortunately, none are used in the routine practice because they do not improve the diagnostic or prognostic accuracy $[8,9]$. Thus, there is an urgent need for the development new serum biomarkers and further introduction into clinical practice for RCC detection and monitoring, and in particular, accurate early diagnostic tools for RCC to obtain better treatment results.

MicroRNAs (miRNAs), a class of small (19 22 nucleotides) noncoding RNAs that regulate the translation of many genes by binding to the untranslated region (3'-UTR) of target mRNAs, are involved in various physiological and pathological processes, in particular development of cancer. Aberrant expression profiles of miRNAs have been identified in a variety of cancers, including RCC [10]. Accumulating evidence demonstrated that those aberrantly expressed miRNAs in cancers are deeply involved in well-known pathways of cancer pathogenesis, including regulation of the cell cycle and proliferation, cell motility and migration, apoptosis and angiogenesis [10]. More importantly, miRNAs are thought to be promising diagnostic and prognostic cancer markers and potential therapeutic tools [11]. Recent studies by our group and others have demonstrated that miRNAs are stably detectable in the circulation and can serve as useful non-invasive biomarkers for cancer [12, 13]. To date, a number of studies have reported circulating miRNAs as diagnostic biomarkers in patients with RCC and identified some specific miRNAs that are increased or decreased in serum or plasma samples from RCC patients [14-23]. However, the development of new circulating miRNA-based diagnostic strategies for RCC especially for early detection of RCC is still very much in its infancy. Furthermore, due to the differences in analytical methodologies and the lack of consensus reference gene, those published miRNA profiling studies in RCC have limited the comparability of data. In particular, most of the reported studies have included only a small number of samples. MiR-200 family (including $\mathrm{miR}-200 \mathrm{a} / \mathrm{b} / \mathrm{c}$ ) were a subset of the most famous miRNAs that play the importance of the epithelial to mesenchymal transition process in the development of cancer, and were reported to be commonly dysregulated in RCC tissues and cell lines [24, 25]. Nevertheless, the expression signature of circulating $\mathrm{miR}-200 \mathrm{a} / \mathrm{b} / \mathrm{c}$ have not been verified in individual serum of patients with RCC and their diagnostic usefulness still need to be elucidated. Therefore, the goal of this study was to evaluate the expression levels of miR-200a/b/c in serum samples of RCC patients and to explore whether circulating $\mathrm{miR}-200 \mathrm{a} / \mathrm{b} / \mathrm{c}$ were useful diagnostic biomarker for distinguishing RCC patients, in particular, early stage RCC patients, from noncancer controls.

In the present study, by employing a hydrolysis probe -based quantitative reverse-transcription PCR (RT -qPCR) assay to retrospectively analyze the levels of $\mathrm{miR}-200 \mathrm{a} / \mathrm{b} / \mathrm{c}$ in individual serum from RCC patients and controls that arranged in two stages, we confirmed that the serum contents of miR-200a, but not miR-200b and miR-200c, were significantly decreased in the RCC patients, especially in early stage of RCC (stage I), and could be of potential use as novel early diagnostic markers of RCC. Moreover, we observed that miR-200a was also significantly downregulated in human RCC 
urine samples. Further studies on the functions and mechanisms of miR-200a in RCC revealed that miR200a represented a putative tumor-suppressive miRNA that it could inhibit cell proliferation and induce cell cycle arrest in RCC cell lines by directly targeting E2F Transcription Factor 3 (E2F3). Altogether, these results uncover that miR-200a may represent a new early diagnostic and therapeutic target in RCC.

\section{Materials and methods}

\section{Study population and sample collection}

The present study enrolled 99 serum samples from RCC patients, all of whom were newly diagnosed and were treated at Jinling Hospital (Nanjing, China) between 2011 and 2015. Patients with acute infections or other types of cancer were excluded from this study. In addition, 27 urine samples were drawn from these patients. Meanwhile, a total of 99 individuals who were recruited from a large pool of individuals seeking a routine health checkup at Jinling Hospital and showed no evidence of disease were selected as non-cancer controls. Blood and urine samples were obtained prior surgery. A total of $3 \mathrm{~mL}$ venous blood was collected from each study participant after $12 \mathrm{~h}$ of overnight fasting. Urine samples (about $10 \mathrm{ml}$ each) were collected in the early morning. Each blood or urine sample was immediately centrifuged at $1500 \mathrm{~g}$ for $10 \mathrm{~min}$ at room temperature and then centrifuged at $12,000 \mathrm{~g}$ for $5 \mathrm{~min}$ at $4{ }^{\circ} \mathrm{C}$ to completely remove the cell debris. The supernatant was transferred to a fresh tube and stored at $-80^{\circ} \mathrm{C}$ until miRNA analysis.

Surgical tissue specimens (paired normal and cancerous tissues) were obtained from another subset of 10 patients with RCC between 2012 and 2016 at the Department of Urology, Jinling Hospital (Nanjing, China). Tissue samples were immediately frozen in liquid nitrogen and stored at $80^{\circ} \mathrm{C}$ until RNA and protein extraction.

All the patients underwent a tumorectomy before any adjunctive therapy. Pathology specimens from all patients enrolled in the study were centrally reviewed using the current WHO classification scheme. Tumor staging was performed using the 2010 TNM staging system. Written informed consent was obtained from all patients and healthy participants prior to the study. The study protocol was approved by the ethics committees of Jinling Hospital and performed in accordance with the Declaration of 1975 Helsinki. The detailed clinicalpathological features of the patients are presented in Table 1.

\section{Cell culture and transfection}

Human RCC cell lines ACHN, Caki-1, 786-O and the immortalized primary human proximal tubular cell HK-2 were obtained from Shanghai Cell Bank, Chinese Academy of Sciences (Shanghai, China). ACHN cells were cultured in MEM-NEAA medium (GBICO, Beijing, China), Caki-1 cells were cultured in McCoy's 5A medium (Sigma-Aldrich, St Louis, MO, USA), 786-O cells were cultured in RPMI-1640 medium, HK-2 cells were cultured in DMEM/F12 medium (GBICO), and the A498 cells was purchased from Cell Resource Center, IBMS, CAMSI/PUMC and grown in MEM-NEAA medium. The above five culture mediums were supplemented with $10 \%$ fetal bovine serum (FBS, Gibco), $10 \mathrm{U} /$ $\mathrm{ml}$ penicillin/streptomycin (Invitrogen) and all cell lines were grown at $37{ }^{\circ} \mathrm{C}$ in a humidified incubator with $5 \%$ $\mathrm{CO}_{2}$.

MiRNA overexpression or inhibition was achieved by transient transfection miRNA mimics or inhibitors (GenePharma Co. Ltd., Shanghai, China) using Lipofectamine 2000 (Invitrogen, Carlsbad, CA, USA). Briefly, RCC Cells were seeded in 6-well plates, when the cells were approximately $70 \% \sim 80 \%$ confluent, equal amount $(100 \mathrm{pmol})$ of miRNA mimics, miRNA inhibitors or scrambled ncRNA were transfected using Lipofectamine 2000 according to the manufacturer's instructions. The cells were harvested and total RNAs or protein were extracted $24 \mathrm{~h}$ or $48 \mathrm{~h}$ after transfection, respectively.

\section{RNA extraction and quantitative real-time PCR analysis}

For the RT-qPCR assay for miRNA levels in serum and urine samples, total RNA was isolated from $100 \mu \mathrm{L}$ serum or $200 \mu \mathrm{L}$ urine with a 1-step phenol/chloroform purification protocol as previously described [26]. A hydrolysis probe-based RT-qPCR assay was performed according to the manufacturer's instructions $(7500 \mathrm{Se}$ quence Detection System, Applied Biosystems, Carlsbad, CA) as described previously [27]. The relative content of serum miRNAs was normalized to an endogenous control let- $7 \mathrm{~d} / \mathrm{g} / \mathrm{i}$, which shows low variability between cancerous patients and normal controls, and were calculated using the $2^{-\Delta C q}$ method [28]. On the other hand, due to none suitable reference gene has been reported for urine miRNA quantification, the absolute concentrations of urinary miRNA were calculated used a calibrator that developed with corresponding synthetic miRNA oligonucleotides as described previously [26]. Each RT-qPCR assay was run in triplicate.

To evaluate the efficiency for cell transfection by using miRNA mimics, inhibitors or scrambled control, total RNA of RCC cells were extracted with TRizol reagent (Invitrogen, Carlsbad, CA) according to the manufacturer's protocol. Equal amounts $(1 \mu \mathrm{g})$ of RNA were reverse transcript into cDNAs using specific primers from Applied Biosystems. Subsequently, hydrolysis probe-based RT-qPCR was performed using primers, probes (Applied Biosystems) and the reverse transcription reagents (Takara, Dalian). Mature miRNAs were measured in accordance with the manufacturer's 
Table 1 Demographic and clinical features of the renal cell carcinoma (RCC) patients and normal controls in this study ${ }^{1}$

\begin{tabular}{|c|c|c|c|c|c|c|c|}
\hline \multirow[t]{3}{*}{ Variables } & \multicolumn{3}{|l|}{ Training phase } & \multicolumn{3}{|l|}{ Validation phase } & \multirow{3}{*}{$\begin{array}{l}\text { RCC tissue } \\
\\
n=10\end{array}$} \\
\hline & \multirow{2}{*}{$\begin{array}{l}\text { Normal controls } \\
n=26\end{array}$} & \multirow{2}{*}{$\begin{array}{l}\text { RCC } \\
n=26\end{array}$} & \multirow{2}{*}{$\begin{array}{l}P \text { - } \\
\text { value }\end{array}$} & \multirow{2}{*}{$\begin{array}{l}\text { Normal controls } \\
n=73\end{array}$} & \multirow{2}{*}{$\begin{array}{l}\text { RCC } \\
n=73\end{array}$} & \multirow{2}{*}{$\begin{array}{l}P- \\
\text { value }\end{array}$} & \\
\hline & & & & & & & \\
\hline Average age (years) & $51.7 \pm 8.2$ & $53.7 \pm 10.5$ & $0.430^{2}$ & $54.9 \pm 8.0$ & $52.7 \pm 13.3$ & $0.234^{2}$ & $55.7 \pm 10.5$ \\
\hline Age (years) & & & $0.482^{3}$ & & & $0.725^{3}$ & \\
\hline$\leq 59$ & 22 & 20 & & 48 & 50 & & 7 \\
\hline$>59$ & 4 & 6 & & 25 & 23 & & 3 \\
\hline Sex & & & $0.080^{3}$ & & & $0.118^{3}$ & \\
\hline Male & 14 & 20 & & 30 & 21 & & 7 \\
\hline Female & 12 & 6 & & 43 & 52 & & 3 \\
\hline Smoking status & & & $0.714^{3}$ & & & $0.644^{3}$ & \\
\hline Ever and Current & 4 & 5 & & 12 & 10 & & 2 \\
\hline Never & 22 & 21 & & 61 & 63 & & 8 \\
\hline Alcohol consumption & & & $0.532^{3}$ & & & $0.682^{3}$ & \\
\hline Ever or Current & 6 & 8 & & 14 & 16 & & 3 \\
\hline Never & 20 & 18 & & 59 & 57 & & 7 \\
\hline \multicolumn{8}{|l|}{ Histological types } \\
\hline Clear cell carcinoma & - & 26 & & - & 73 & & 10 \\
\hline Other & - & 0 & & - & 0 & & 0 \\
\hline \multicolumn{8}{|l|}{ TNM Stage } \\
\hline । & - & 19 & & - & 52 & & 3 \\
\hline$\|$ & - & 3 & & - & 11 & & 6 \\
\hline III & - & 0 & & - & 2 & & 1 \\
\hline IV & - & 3 & & - & 5 & & 0 \\
\hline Unknown & _- & 1 & & - & 3 & & 0 \\
\hline
\end{tabular}

${ }^{1}$ Data are mean \pm standard deviation. ${ }^{2} P$, student- $t$ test; ${ }^{3} P$, two-sided $x^{2}$ test

instructions (7900HT Sequence Detection System, Applied Biosystems, Carlsbad, CA). The threshold cycle values were used to calculate the relative difference in miRNA levels. U6 RNA was used as an internal control in these RT-qPCRs and the miRNA relative expression was calculated using the power formula: $2^{-\Delta \Delta C q}, \triangle \mathrm{Cq}=$ $\mathrm{Cq}_{\text {miRNA }}-\mathrm{Cq}_{\mathrm{U} G}$, and $\Delta \Delta \mathrm{Cq}=\Delta \mathrm{Cq}_{\text {experimental }}$ group -

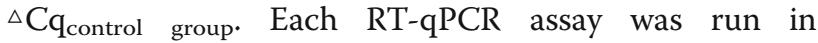
triplicate.

\section{MiRNA target genes prediction and luciferase reporter assay}

The potential target genes of miRNA were predicted using the 3 web-based analytical algorithms including TargetScan, PicTar and miRanda. To further determine whether miRNA directly targeted the predicted gene by binding to the presumed sites in the 3 '-UTR of the mRNA, pMiR-Report plasmid (Ambion, Austin, TX, USA) were used to introduce the portion of the 3' UTR of target gene mRNA containing the putative binding site for miRNA. The insertion was confirmed as correct by sequencing. RCC cells were co-trans fected with the pMiR-Report vectors containing the target 3'-UTR with wild-type (WT) or mutant (MT) sequences and miRNA mimics, inhibitors or scrambled control, in addition, $2 \mu \mathrm{g}$ of a $\beta$-galactosidase expression plasmid (Ambion) was co-transfected simultaneously and used as a transfection efficiency control. After $24 \mathrm{~h}$ after transfection, the cells were lysed and luciferase activity was measured using a luciferase assay kits (Promega, Madison, WI, USA) by luminometer.

\section{Western blotting}

Tissue specimens and cells were lysed in RIPA buffer with proteinase inhibitor. The protein concentrations were assayed by BCA method. Standard western blotting was performed as previously described [29]. The primary antibody against E2F3 (ab50917, 1:500) was purchased from Abcam, and the primary antibody against GAPDH (\#5174, 1:2000) was purchased from Cell Signaling Technology. The secondary antibodies were anti-Rabbit IgG (Cell Signaling Technology, \#7074, 1:3000). 


\section{Cell proliferation analysis}

The cell proliferation was examined using EdU assay (RiboBio Co., Ltd., Guangzhou, China) as previously described [30]. In brief, RCC cells transfected with miR-200a mimics, inhibitors or the corresponding negative control were seeded in 48-well plates at a density of $2 \times 10^{3}$ cells per well and further grown under normal culture conditions for $48 \mathrm{~h}$. After the incubation, the proliferation rate of the RCC cells was measured using the EdU assay kit according to manufacturer's instructions. After staining, the cells were captured by photomicroscopy (BX51 Olympus, Japan). The experiment was performed in triplicate.

\section{Cell cycle assay}

Cell cycle profile changes were assessed by flow cytometry using PI staining to measure the DNA content. In detail, RCC cells transfected with miR-200a mimics, inhibitors or the corresponding negative control through transient transfection and following $48 \mathrm{~h}$ culture. The cells were then collected and washed once with PBS, resuspended in $300 \mu \mathrm{L}$ of PBS, and fixed with $700 \mu \mathrm{L}$ of $70 \%$ ethanol at $4{ }^{\circ} \mathrm{C}$ for overnight. Fixed cells were washed twice in PBS and stained with $1 \mu \mathrm{g} / \mathrm{ml}$ propidium iodide (PI) solution containing $10 \mu \mathrm{g} / \mathrm{ml}$ RNase (Sigma, USA) in PBS at $37{ }^{\circ} \mathrm{C}$ for $1 \mathrm{~h}$ in the dark. Stained cells were then analyzed using a flow cytometry with the FACSCalibur flow cytometer (BD Biosciences, San Jose, CA, USA).

\section{Statistical analysis}

The statistical analyses were performed with SPSS software (version 23.0; IBM SPSS Statistics) and GraphPad Prism 6.0 (GraphPad, San Diego, CA, USA). The miRNA data were presented as the mean (SE) and other variables were expressed as the mean (SD). The nonparametric Mann-Whitney $U$-test was used to compare differences in variables between groups. A $P$ value $<0.05$ was considered statistically significant. We constructed ROC curves and calculated the area under the ROC curve (AUC) to identify the diagnostic usefulness of miRNA for RCC patients.

\section{Results}

\section{Serum miR-200a decreases in patients with RCC}

A two-phase case-control study was designed to verify the serum miR-200a/b/c signature in individual samples of RCC patients and further test whether they have the potential as surrogate markers for RCC diagnosis. Firstly, the expression levels of $\mathrm{miR}-200 \mathrm{a} / \mathrm{b} / \mathrm{c}$ were examined in a cohort of 26 RCC patients and 26 controls (referred as training phase) by an individual RT-qPCR assay. The demographic and clinical features of RCC patients were summarized in Table 1, no significant differences were found between the RCC patients and the control individuals based on age distribution, sex, smoking status and alcohol consumption status. Of the three miRNAs, only miR-200a was significantly decreased in RCC patients as compared with normal controls $(P<0.001)$, while the other two members (miR-200b and miR-200c) didn't displayed statistically difference between patients and controls $(P=0.618$ and $P=0.163$, respectively) (Fig. 1 a-c).

Subsequently, the serum miR-200a expression signature was examined by RT-qPCR in another larger cohort consisting of $73 \mathrm{RCC}$ patients and 73 matched controls (referred as validation phase) (Table 1). Consistent with the results from the training phase, the serum levels of miR-200a were significantly lower in the cancer patients than in the control individuals $(P<0.001)$ (Fig. 1d). Furthermore, the concentrations of the miR-200a in all individuals in the training and validation phases consistently significanty decreased in RCC patients (Fig. 1e). Therefore, miR-200a was selected as candidate for further analyses.

\section{MiR-200a levels in RCC at different stages}

Because RCC patients with cancers in tumor, node, metastasis (TNM) stage I or II can undergo complete resection of tumors and early detection of this cancer will most likely improve survival rate, we compared serum miR-200a levels in RCC at stage I or II with that in normal controls, and found that miR-200a levels were significantly different between early-stage RCC and controls $(P<0.001$ and $P<0.05$, respectively), suggesting that miR-200a could differentiate early-stage RCC patients from healthy controls (Fig. 1f). In addition, we also compared miR-200a levels in RCC at different stages and no markedly difference was observed among different stages (Fig. 1f).

\section{ROC curve analysis}

To evaluate the diagnostic usefulness of the serum miR-200a for detecting RCC, receiver operating characteristic curves (ROC) were constructed with the samples used in the training and validation phases. The analysis yielded the area under the ROC curve (AUC) is 0.836 (95\% CI, 0.728-0.944) for the training phase, the AUC is $0.702(95 \% \mathrm{CI}, 0.618-0.785)$ for the validation phases, and the AUC for all the RCC is 0.724 (95\% CI, 0.6550.793 ) in both the training and validation phases (Fig. 2a-c).

To further evaluate the early diagnostic value of miR-200a for RCC, we conducted ROC curve analysis for early-stage RCC (stage I and II) and control groups. The AUC for miR-200a was 0.740 (95\% CI, $0.667-$ 0.814), 0.700 (95\% CI, 0.544-0.847), and 0.733 (95\% CI, 0.662-0.804) for RCC patients at stage I, stage II, and 

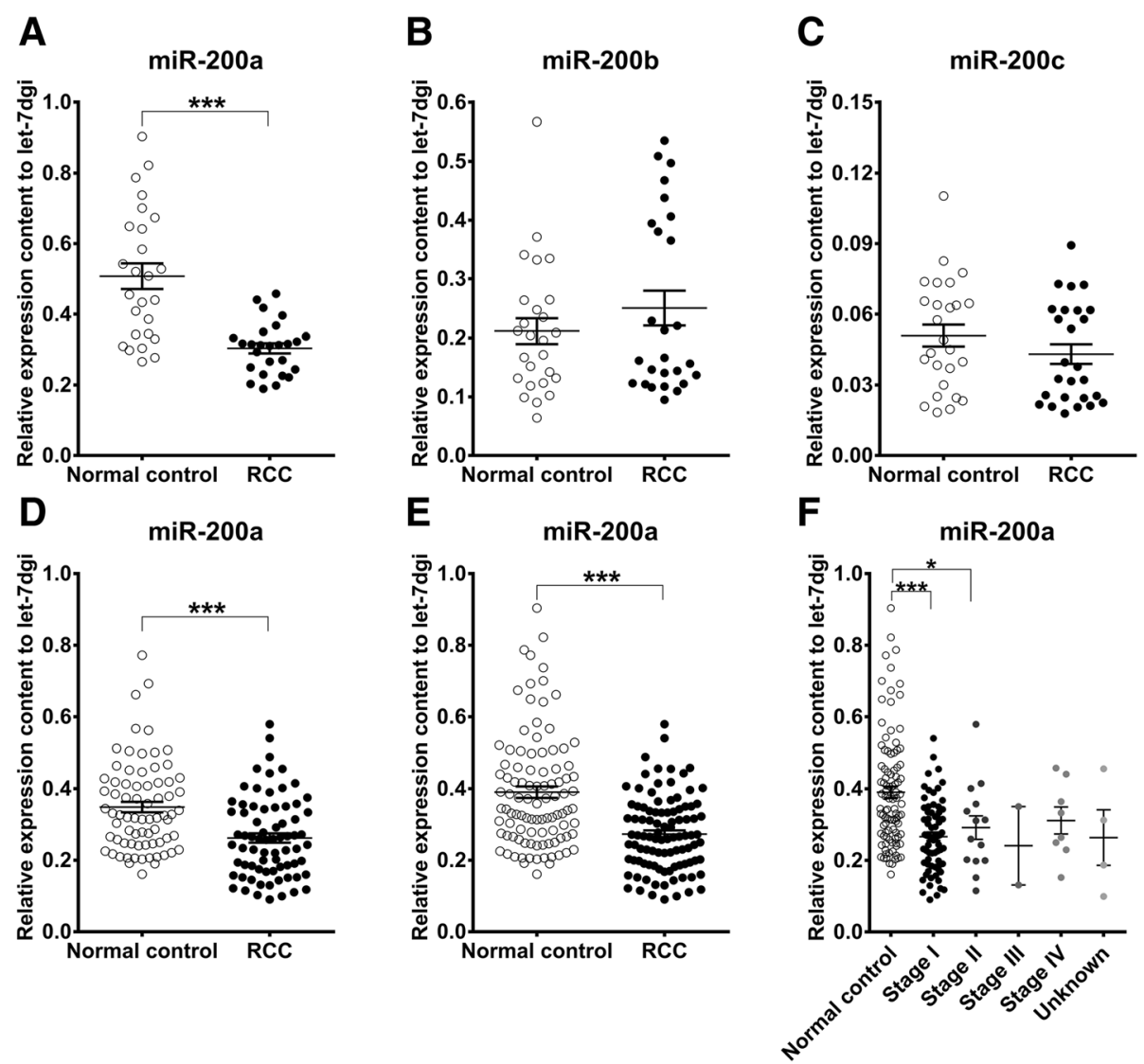

Fig. 1 The expression levels of the examined miRNAs in serum in the training and validation phase. a-c The relative expression levels of serum miR-200a (a), miR-200b (b), and miR-200c (c) in the training phase. d, e The relative expression levels of serum miR-200a in the validation phase (D) and in the combined two phases (e). $\mathbf{f}$ The relative expression levels of serum miR-200a in RCC cases at different stages enrolled in the training and validation phases. The relative expression levels of miRNAs were normalized to let- $7 \mathrm{~d} / \mathrm{g} / \mathrm{i}$ and calculated using the $2^{-\Delta C a}$ method. Each point represents the mean of triplicate samples. Each $P$-value was derived from a nonparametric Mann-Whitney $U$-test. ${ }^{*} P<0.05{ }^{* * *} P<0.001$

stages I-II, respectively (Fig. 2d-f). With an optimal cutoff value 0.3174 , the sensitivity was $71.83 \%$ and the specificity was $61.62 \%$ for stage I RCC. These results demonstrate that serum miR-200a hold the potential to detect RCC at its earlier stages when surgical resection may be curative.

\section{Urinary concentrations of the miR-200a in RCC patients}

We further assessed the miR-200a concentrations in urine samples from $27 \mathrm{RCC}$ patients and 27 controls. The RT-qPCR assay for measuring the urine miRNA concentration was reliable and reproducible [26]. The urinary concentrations of miR-200a in the RCC patients were significantly lower than in the controls $(P<0.001)$. An ROC curve analysis showed that the AUC for urinary miR-200a was 0.826 (95\% CI, 0.717-0.935) for differentiation RCC patients from controls (Fig. 3).

\section{Identification of target gene of miR-200a}

Our previous studies have demonstrated that the expression of miR-200a is significantly deceased in RCC tissues and cell lines (A498, ACHN and Caki1) when compared with their corresponding controls [31], to better understand the potential biological functions of miR-200a in RCC pathogenesis, we identify the miR-200a targets and conduct an in silico search using Targetscan, miRanda, and PicTar. All three algorithms predicted E2F transcription factor 3 (E2F3) as the potential target of miR-200a. The predicted interactions between miR-200a and the targeting sites within the 3'-UTR of E2F3 was illustrated in Fig. 4a. There were two potential miR-200a target sites in the 69-75 and 2603-2610 of E2F3 mRNA 3 '-UTR sequence. The minimum free energy values of the two hybrids were $-22.7 \mathrm{kcal} / \mathrm{mol}$ and $-20.5 \mathrm{kcal} /$ mol, respectively, which are well within the range of genuine miRNA-target pairs. Furthermore, the miR200a-binding sequences in E2F3 3'-UTR were highly conserved across species (Fig. 4a).

To further support the above data, we subsequently wish to explore the association between the expression of miR-200a and the levels of E2F3 in tissues specimens and RCC cell lines. The levels of 

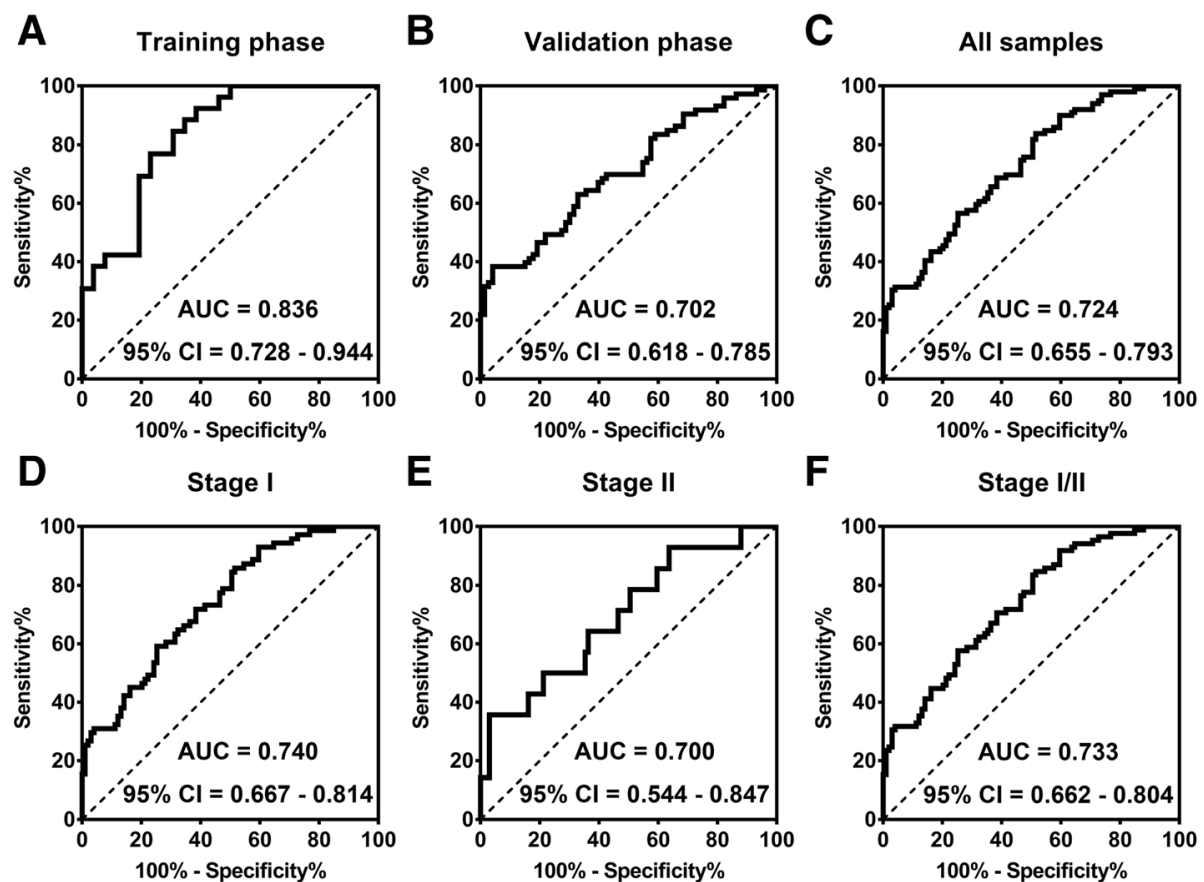

E

Stage II

$\mathbf{F}$

Stage I/II
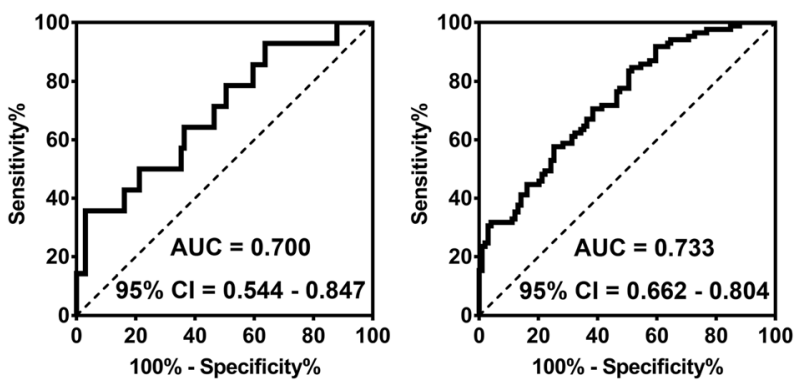

Fig. 2 The receiver operating characteristic curve (ROC) analysis for the discriminative ability between RCC patients and normal controls by the serum miR-200a. a-c ROC curves for the serum miR-200a to differentiation RCC patients from normal controls in the training phase (a), in the validation phase (b), and in the combined two phases (c). d-f ROC curves for the serum miR-200a to discern stage I RCC cases (d), stage II RCC cases (e), and stage I-II RCC cases from controls in the training and validation sets (f)

E2F3 were firstly assessed in the matched tumor and non-tumor tissues from 10 ccRCC patients, for which were used previously to examine the expression pattern of tissue miR-200a. It was shown that the expression of E2F3 is significantly increased in tumor tissues compared with healthy tissues $(P<0.01)$ (Fig. 4b-c). In addition, the E2F3 protein level was also markedly elevated in renal carcinoma cell lines $(P<$ 0.001) (Fig. 4d). Thus, based on both computational predictions and the inverse expression between the levels of miR-200a and the levels of E2F3 protein, E2F3 was deduced to be a miR-200a target in RCC.

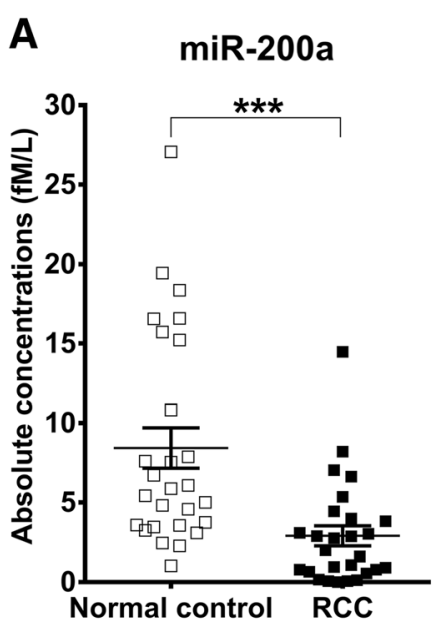

B

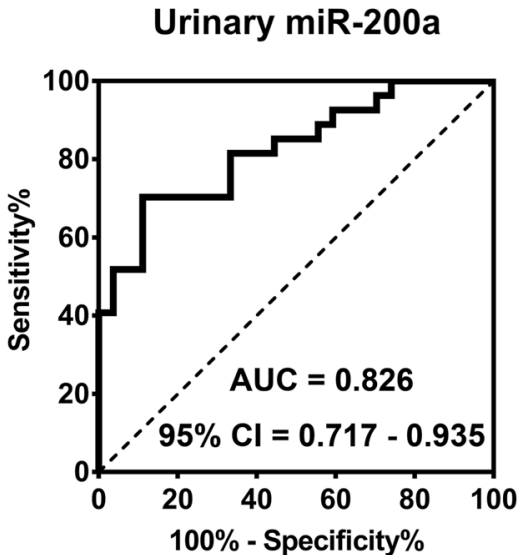

Fig. 3 The alteration and the diagnostic performance of the urinary miR-200a between the RCC patients and normal controls. aThe absolute concentrations of miR-200a in the urine samples from RCC patients and normal controls. ROC curve for the urinary miR-200a to discern RCC patients from normal controls. $\mathbf{b}$ The absolute concentrations of urinary miR-200a were calculated using the corresponding calibrator. Each point represents the mean of triplicate samples. $P$-value was derived from a nonparametric Mann-Whitney $U$-test. ${ }^{* * *} P<0.001$ 

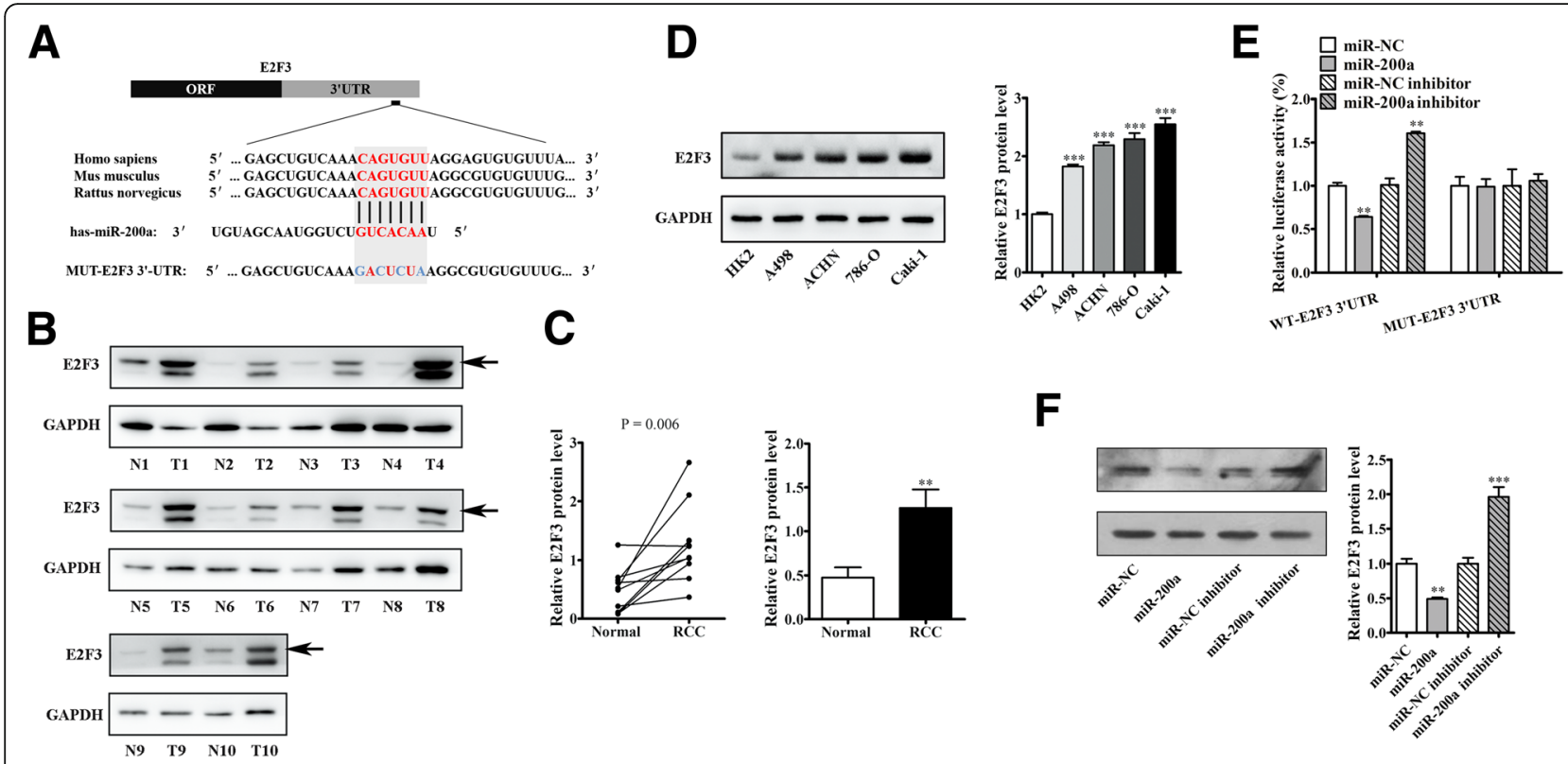

Fig. 4 E2F3 is downregulated by miR-200a in RCC. a Schematic diagram showing the design of constructs containing wild-type and mutant $3^{\prime} \mathrm{UTR}$ sequence of E2F3 that binding with miR-200a. The miR-200a complementary seed region and the compensatory mutation sites are indicated in red and blue, respectively. $\mathbf{b}, \mathbf{c}$ Expression of E2F3 in renal cell carcinoma tissues were assessed by western blot (b), and the intensities of individual bands were analyzed by Image J software and normalized with GAPDH to calculate the relative levels of E2F3 (c). d Expression of E2F3 in renal carcinoma cells were detected by western blot. The intensities of individual bands were analyzed by Image J software and normalized with GAPDH to calculate the relative levels of E2F3, as shown at the right bottom. e E2F3 WT-3'UTR or E2F3 Mut-3'UTR pMiRReport luciferase vector along with the indicated miR-NC, miR-200a mimics, miR-NC inhibitor or miR-200a inhibitor were co-transfected into ACHN cells for $48 \mathrm{~h}$ and luciferase assays were performed. Luciferase activity was assessed by normalization of firefly luciferase activity to $\beta$ galactosidase activity. f E2F3 protein levels in miR-NC, miR-200a mimics, miR-NC inhibitor, or miR-200a inhibitor transfected ACHN cells were measured by western blot analysis. The intensities of individual bands were analyzed by Image J software and normalized with GAPDH to calculate the relative levels of E2F3, as shown at the right bottom. Results were collected from three independent experiments, with triplicate repeats for each experiment. Data are shown as the mean \pm s.d. ${ }^{* *} P<0.01 ;{ }^{* * *} P<0.001$

\section{Validation of E2F3 as a direct target of miR-200a}

To verify whether E2F3 is a direct target of miR-200a in RCC, the 3'-UTR of human E2F3 mRNA containing the putative binding sites (2603-2610) of miR-200a was generated and cloned into the luciferase construct pMIR-reporter plasmid. The recombination plasmid was co-transfected into RCC cells along with miR-200a mimics, miR-200a inhibitors or scrambled negative control RNAs. Luciferase assay revealed that ectopic expression of miR-200a significantly reduced the activity of the luciferase reporter gene fused to the E2F3 3'-UTR compared with scrambled control in ACHN cells $(P<0.01)$. In contrast, miR-200a did not decrease the luciferase activity of a mutant construct that contained substitutions at 4 nucleotides of E2F3 gene within the miR-200a-binding site (Fig. 4e). In concordance with these results, western blotting analyses proved that endogenous E2F3 protein levels were downregulated in miR-200aoverexpressing cell lines and were enhanced when the expression of miR-200a was repressed (Fig. 4f). These results suggested that E2F3 was a direct target of miR-200a.

\section{MiR-200a attenuated RCC cell proliferation and induced} cell cycle arrest at G0/G1 phase in vitro

We next focused on studying the roles of miR-200a/ E2F3 regulation axis. It is well known that E2F3 was generally considered to function as oncogene and can promote cell proliferation through promoting the G1/S transition in various tumors, and its overexpression was strongly associated with tumor invasive phenotype and high tumor grade in a subset of cancers [32, 33]. We firstly evaluated the effects of miR-200a on RCC cell proliferation using the EdU assay. For this purpose, ACHN cells were transfected with miR-200a mimics, inhibitors or scrambled control, respectively. The cell proliferation assay revealed that overexpression of miR-200a significantly reduced the growth rate of ACHN cells ( $P$ $<0.01$, Fig. 5a). In contrast, silencing of miR-200a expression markedly facilitated proliferation of ACHN cells $(P<0.05$, Fig. 5a). To further validate the role of miR-200a in renal carcinoma cell proliferation, we subsequently performed cell cycle assay when miR-200a was upregulated or downregulated in ACHN cells, respectively. As shown in the Fig. 5b, compared with the controls, A498 and ACHN cells 

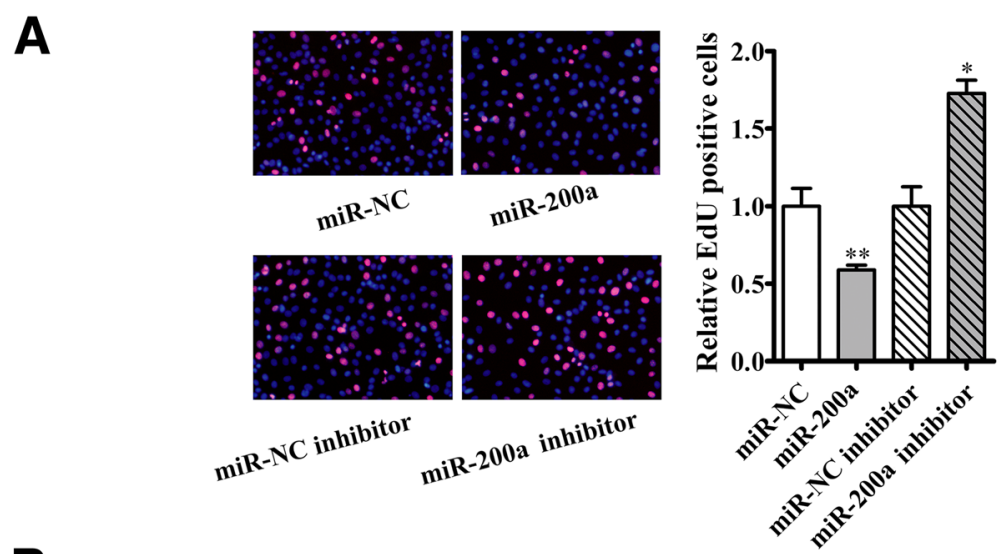

B
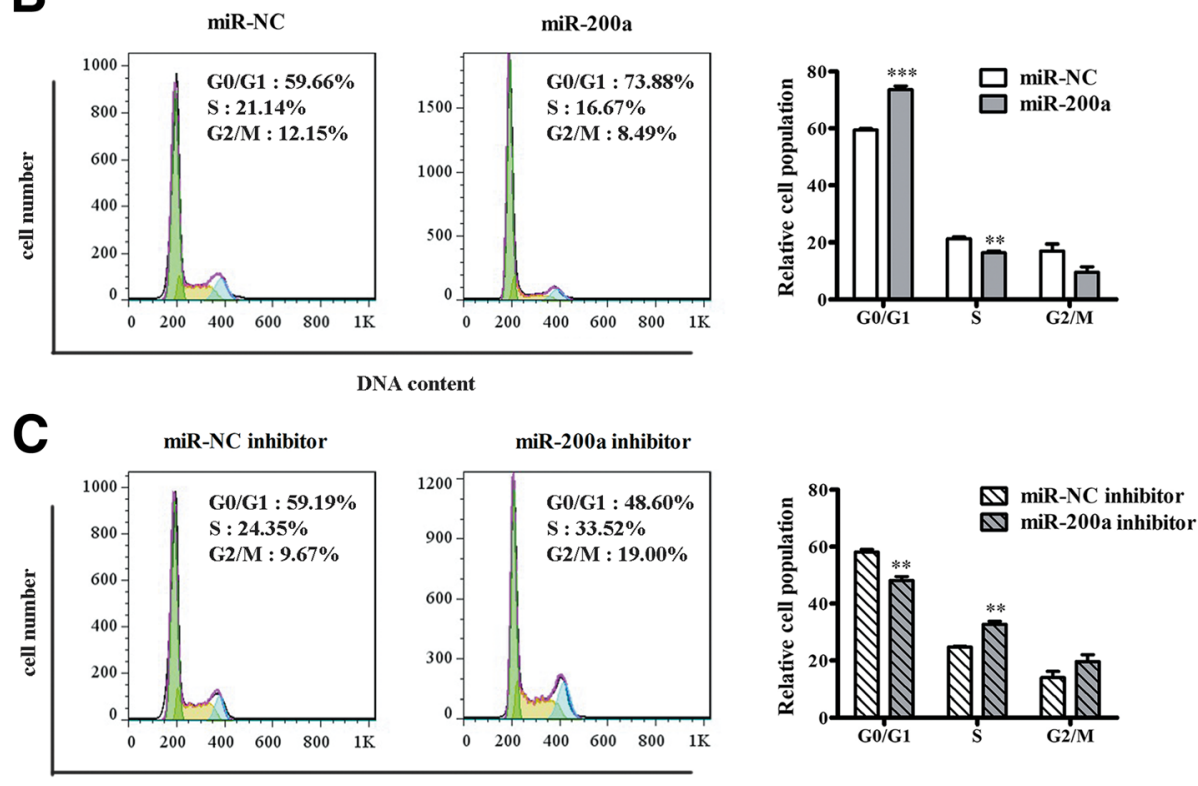

DNA content

Fig. 5 MiR-200a expression suppresses renal carcinoma cell proliferation and induced cell cycle arrest at G0/G1 phase in renal carcinoma cells. a EdU proliferation assay analysis of the effect of miR-200a overexpression or inhibition on the proliferation of renal carcinoma cells. The EdU proliferation assay was performed $48 \mathrm{~h}$ after the transfection of ACHN cells with miR-NC, miR-200a mimics, miR-NC inhibitor, or miR-200a inhibitor, the representative images are shown and the ratio of EdU-positive ACHN cells are also shown at the right bottom. The cells with red fluorescence are in the $\mathrm{S}$ phase of mitosis, and the cells with blue fluorescence represent all of the cells. $\mathbf{b}, \mathbf{c}$ Flow cytometry analysis of the effect of miR-200a overexpression (b) or inhibition (c) on the cell cycle profile changes of renal carcinoma cells. Fluorescent-activated cell sorting analysis were performed $48 \mathrm{~h}$ post-transfection with miR-NC, miR-200a mimics, miR-NC inhibitor, or miR-200a inhibitor in ACHN cells. After transfection, the cells were collected and washed once with PBS, resuspended in $300 \mu \mathrm{L}$ of PBS, and fixed with $700 \mu \mathrm{L}$ of $70 \%$ ethanol at $4{ }^{\circ} \mathrm{C}$ for overnight. Fixed cells were washed twice in PBS and stained with $1 \mu \mathrm{g} / \mathrm{ml}$ propidium iodide (PI) solution containing $10 \mu \mathrm{g} / \mathrm{ml} \mathrm{RNase}$ (Sigma, USA) in PBS at $37^{\circ} \mathrm{C}$ for $1 \mathrm{~h}$ in the dark. Stained cells were then analyzed using a flow cytometry with the FACSCalibur flow cytometer (BD Biosciences, San Jose, CA, USA), and the relative cell population were shown at the right bottom. Representative experiment was performed in triplicate. Data are shown as the mean \pm s.d. ${ }^{* *} P<0.01 i^{* * *} P<0.001$

transfected with miR-200a mimics had a significantly higher percentage of cells in G0/G1 phase and a significantly lower percentage of cells in $\mathrm{S}$ phase, while inhibited miR-200a expressions had opposite effects, suggesting that miR-200a induces G0/G1 arrest (Fig. $5 \mathrm{c})$. Taken together, the results indicate that miR-200a inhibit RCC cell proliferation and induce cell cycle arrest at G0/G1 phase via silencing E2F3.

\section{Discussion}

Accumulating evidence demonstrated that miRNAs in serum and plasma are promising non-invasive biomarkers for diagnosing of various human cancers, including RCC [10]. Nevertheless, although there is a rapidly expanding literature on RCC serum miRNA expression patterns, the results regarding the dysregulated miRNAs from different research is conflicting. In 
addition, the use of circulating miRNA as a potential biomarker for RCC, especially for early diagnosis of RCC is still very much in its infancy. Thus, profiles of circulating miRNAs differ need to be further investigated in RCC patients, particularly in the early stage of RCC. In this study, we assessed the relation between the expression pattern of the most famous EMT-related miRNAs $(\mathrm{miR}-200 \mathrm{a} / \mathrm{b} / \mathrm{c})$ and diagnosis of RCC. We performed a two-phase case-control study to screen the miR-200a/b/ c profile in serum from the RCC patients and noncancer controls, and identified that miR-200a, but not miR-200b and miR-200c, was significantly downregulated in the serum of RCC patients. More importantly, the miR-200a showed the diagnostic ability for discriminating the early-stage RCC patients from the control subjects. In addition, we also confirmed that the expression signature of miR-200a in RCC urine was consistent with RCC serum. Bioinformatics analysis predicted E2F3 as a conserved target of miR-200a. Mechanism study revealed that miR-200a plays a critical role in attanuing RCC cell proliferation through regulating E2F3 expression. Taken together, our results demonstrated that the serum miR-200a signature may utilize as a potential non-invasive biomarker in detecting the early-stage RCC and in helping for identification of therapeutic targets for RCC.

Early diagnosis of asymptomatic RCC patients is crucial for formation of appropriate treatment choices and leads to better prognostic outcome. The challenge at present is to identify new molecular markers with diagnostic significance to distinguish which RCC patients are at early stage and would benefit most from timely medical intervention. Obviously, biomarkers presented in blood are preferable than markers obtained from other tissues. For this purpose, many attempts have been performed aimed at recognizing novel informative RCC biomarkers applicable for early detection of the disease and a number of serological markers including VEGF, TATI have been reported to have diagnostic potential for early RCC $[8,9]$. However, their efficiency remains quite different and insufficient in sensitivity and/or specificity have limited their clinical feasibility. Recent studies by both our group and others have implied that cell-free miRNAs stably detectable in circulation are potential novel biomarkers for cancer diagnosis and prognosis, nevertheless, little is known about the relationship between serum miRNAs and early diagnosis in RCC. At present, a number of studies have investigated the utility of circulating miRNAs as a diagnostic biomarker for RCC. For instance, miR-508-3p showed significantly downregulation in RCC patient and may serve as novel diagnostic markers for RCC [15]. In the meanwhile, Redova et al. found that the combination of serum miR-378 and miR-451 enable identification of RCC from controls [16]. Nevertheless, a contemporaneous study from Hauser et al. reported conflicting results that circulating serum levels of four miRNAs including miR-378 showed no significantly different between patients with RCC and non-malignant controls [17]. Interestingly, an early similar research from the same group still identified another circulating miRNA, miR-1233, increased in RCC patients and has the potential as biomarker for RCC patients [14]. The diagnostic usefulness of serum miR-1233 was further proved in a recent publication, the investigators claimed that using a panel of 2 serum miRNAs (miR-141 and miR-1233) RCC can be diagnosed with $100 \%$ sensitivity and $73.3 \%$ specificity [22]. MiR-210 is a well-known hypoxamirs in several types of tissues and cells, and it contributes to cellular adaptation to hypoxic environments [34]. Emerging evidence has demonstrated that the serum levels of miR-210 were significantly higher in RCC patients than in controls, fur thermore, serum miR-210 level tended to be higher in patients with metastasis at diagnosis when compared with patients without metastasis $[18,19]$. Moreover, detection of serum miR-210 combined with serum miR-378 showed a more powerful non-invasive diagnostic biomarker with high accuracy for RCC patients [20]. Although there are increasing evidence of miRNAs in circulation to serve as novel non-invasive biomarkers in RCC, we noticed that there is only few miRNAs such as miR-210 and miR-1322 overlap among those previous studies. We speculate that this inconsistency may be introduced not only by sample properties but also by the methodological issues, including differences in sample preservation and preparation and the analytical sensitivity, specificity and robustness of the various assays used. On the other hand, inadequate normalization strategies that were used in different studies are also likely to generate questionable results. Actually, the synthetic cel-miR-39, miR-16, U6, or 5s rRNA were applied to normalize the circulating miRNA expression levels in those existing studies, respectively. In our present study, we normalized the serum miR-200a levels by utilized a combination of three miRNAs, namely let $-7 \mathrm{~d} / \mathrm{g} / \mathrm{i}$, for which showed highly stable levels across numerous healthy controls and patients with a variety of different diseases, and was seemed statistically superior to the commonly used reference genes U6, RNU44, RNU48 and miR-16 [28]. Furthermore, the clinical relevance of these circulating miRNAs has not been independently evaluated for the early detection of RCC. In our previous study, we have reported that a 5-miRNAs panel has potential value as an auxiliary clinical diagnostic tool to detect early-stage RCC [27]. Based on the findings and the methodologies in our previous study, as well as the reality that the relationship between serum miR-200a and RCC has never been explored, we further investigated 
the alteration pattern and evaluated the usefulness of the kidney enriched and EMT-associated miR-200a in the serum of RCC patients and controls, and found for the first time, that serum miR-200a was significantly decreased in RCC patients and may have the potential to be served as an auxiliary diagnostic markers for the early detection of RCC.

Understanding the miRNA targets and the molecular mechanisms by which the miRNAs regulate RCC development may promote their clinical application. For instance, a recent study found that the expression levels of miR-18a-5p were markedly increased in RCC tissues and cell lines, moreover, upregulation of miR-18a-5p in RCC cells can enhance cell proliferation, migration, invasion and inhibition of apoptosis, while down-regu lation of miR-18a-5p had the opposite effect. Furthermore, TCGA and prognostic analysis revealed that high miR-18a-5p expression patients had significantly poorer survival. However, the direct targets and potential mechanism of miR-18a-5p involved in RCC were not elucidated, which limited the clinical translation in RCC diagnosing and therapizing [35]. In this study, we identified E2F3 as a direct target of miR-200a in renal carcinoma cells. E2F3 is a member of the E2F transcription factor family, which was involved in the regulation of cell cycle and recognized as an oncogene with strong proliferative potential $[32,33]$. Growing evidence demonstrated that E2F3 was participated in many physiological and pathological processes, and played pivot roles in the development of several types of cancer, including RCC [36-38]. Recent studies demonstrated E2F3 as the direct target of various miRNAs in RCC, such miR-34a and miR-429, to be involved in RCC tumorigenesis and progression [39]. However, up to date, the regulation relationship between miR-200a and E2F3 has never been examined in any disease, especially in RCC. Thus, the roles of miR-200a-E2F3 axis in RCC development and the underlying mechanisms still need to be explored. Herein, in our present study, we showed that E2F3 was also a direct target of miR-200a in RCC. Notably, we observed that overexpression of miR-200a can inhibit cell proliferation and induce cell cycle arrest at G0/G1 phase by negatively regulating E2F3 in RCC cells, while down-regulating miR-200a levels has opposite effects. Thus, it was concluded that down-regulation of E2F3 by miR-200a overexpression may be a key molecular mechanism event in the proliferation and cycle regulation of RCC cells. Nevertheless, in our present study, we only verified that E2F3 is direct target of miR-200a and examined the pathophysiological roles of the miR-200a/E2F3 regulation axis in RCC cells. Notably, another recent study utilizing Gene Expression Omnibus analysis to identify novel potential key genes for the diagnosis, prognosis or targeted therapy of RCC demonstrated that five genes including ENO2, CCND1, PLT1, PLG and VWF may be key factors in RCC pathogenesis. Thus, it is reasonable that other key target genes of miR-200a and other miRNAs that target E2F3 may also involved in the renal carcinoma cell proliferation and migration. Elucidation of the molecular mechanisms of other key genes as well as important miRNA involved in the mediation of RCC development and progression are still warranted in future [40].

In the present study, we also noticed that the diagnostic performance of the urinary miR-200a in the RCC patients seems even better than the serum miR-200a, this results raised the possible that detection of miRNA in urine may be an ideal really non-invasive source of biomarkers for RCC diagnosis, since urine is collected more noninvasively and easily accessible, and fashionable for translation in clinical practice when compared with blood. However, the result of the urinary miR-200a for diagnosing of RCC that presented in our study was very preliminarily and the data was acquired only from a relative small size of urine samples, more additional studies on analyzing the clinical usefulness of urinary miRNAs for RCC diagnosis and prognosis should be performed to verify the feasibility.

The consistent alteration of miR-200a levels in RCC serum, urine, cell lines and tissues in our former and present studies also raised an impossible that the dysregulated miR-200a in RCC serum may be selectively released from RCC cells via mechanisms involving tumor-derived exosomes or microvesicles. Mounting evidence have demonstrated that miRNAs can to be generated by host cells and packaged into EVs, and effectively delivered to a target cell or tissue with intact functionality [41]. Moreover, miRNA in exosomes or microvesicles that delivered to the target cells can regulate the translation of their target genes as well the function of the target cells, and represented a new mediator for inter cellular communication [42, 43]. Actually, one recent study have reported that miR-210 and miR-1233, which were upregulated in the RCC tissues and serum, also showed significantly higher levels in the serum exosomes of ccRCC patients than in healthy individuals [44]. In addition, another study identified an IncRNA, named lncARSR, of which could be incorporated into exosomes from RCC cells and transmitted to sensitive cells, thus disseminating sunitinib resistance [45]. Therefore, characterizing the physiological state and the potential target cells of serum miR-200a in RCC may lead to the application of serum miRNA in the clinic and provide potential therapeutic target for RCC treatment.

\section{Conclusions}

In summary, we identified for the first time a serum miRNA, miR-200a, may serve as a potential non-invasive 
biomarker in detecting the early-stage RCC. Furthermore, we investigated the functions of miR-200a in RCC cells proliferation and cell cycle regulation, and demonstrated miR-200a plays a tumor-suppressive role in RCC by directly inhibiting its targets, E2F3. These findings provide new insight into the potential development of serum miR-200a-based early diagnostic molecular marker of RCC and improve understanding of the novel molecular mechanisms underlying renal carcinoma development.

\section{Abbreviations \\ 3'-UTR: 3'-untranslated region; AUC: Area under receiver operating characteristic curve; E2F3: E2F transcription factor 3; EMT: Epithelial- mesenchymal transition; MiRNA: MicroRNA; RT-qPCR: quantitative real-time polymerase chain reaction; RCC: Renal cell carcinoma; ROC: Receiver operating characteristic curve}

\section{Acknowledgements}

Not applicable.

\section{Funding}

This work was supported by the National Natural Science Foundation of China, grant number: 81772282,81672102 and 81472021 , by the Foundation of Jiangsu Provincial Medical Youth Talent, grant number: QNRC2016893, by the Fund of State Key Laboratory of Analytical Chemistry for Life Science, grant number: 5431ZZXM1601

\section{Availability of data and materials}

All data generated or analysed during this study are included in this published article.

\section{Authors' contributions}

CW, CZ and JJW contributed to the conception and design of the study. YYZ, JH and JG were responsible for recruiting/supplying patients and samples for the study. CW, MD, YYZ, JH, CPZ and XL were all involved with the acquisition and interpretation/analysis of study data. All the authors contributed to drafting and reviewing the manuscript, and all the authors read and approved the final manuscript.

\section{Ethics approval and consent to participate}

Written informed consent was obtained from all patients and healthy participants prior to the study. The study protocol was approved by the ethics committees of Jinling Hospital and performed in accordance with the Declaration of 1975 Helsinki.

\section{Consent for publication}

We have obtained consents to publish this paper from all the participants of this study.

\section{Competing interests}

The authors declare that they have no competing interests.

\section{Publisher's Note}

Springer Nature remains neutral with regard to jurisdictional claims in published maps and institutional affiliations.

\footnotetext{
Author details

${ }^{1}$ Department of Clinical Laboratory, Jinling Hospital, State Key Laboratory of Analytical Chemistry for Life Science, Nanjing University School of Medicine, 305 East Zhongshan Road, Nanjing 210002, China. ${ }^{2}$ State Key Laboratory of Pharmaceutical Biotechnology, Nanjing Advanced Institute for Life Sciences, Nanjing University School of Life Sciences, Jiangsu Engineering Research Center for MicroRNA Biology and Biotechnology, Nanjing University, Nanjing 210046, China. ${ }^{3}$ Department of Science and Technology, Jiangsu Province Hospital of TCM, Nanjing 210029, China. ${ }^{4}$ Department of Urology, Daqing people's Hospital, Daging 163316, China. ${ }^{5}$ Department of Urology, Jinling Hospital, Nanjing University School of Medicine, Nanjing 210002, China.
}

Received: 1 August 2018 Accepted: 14 March 2019

Published online: 06 August 2019

\section{References}

1. Global Burden of Disease Cancer C, Fitzmaurice C, Allen C, Barber RM, Barregard L, Bhutta ZA, Brenner H, Dicker DJ, Chimed-Orchir O, Dandona R, et al. Global, Regional, and National Cancer Incidence, Mortality, Years of Life Lost, Years Lived With Disability, and Disability-Adjusted Life-years for 32 Cancer Groups, 1990 to 2015: A systematic analysis for the global burden of disease study. JAMA Oncol. 2017;3:524-48.

2. Cairns P. Renal cell carcinoma. Cancer Biomark. 2010;9:461-73.

3. Shuch B, Amin A, Armstrong AJ, Eble JN, Ficarra V, Lopez-Beltran A, Martignoni G, Rini Bl, Kutikov A. Understanding pathologic variants of renal cell carcinoma: distilling therapeutic opportunities from biologic complexity. Eur Urol. 2015;67:85-97.

4. MacLennan S, Imamura M, Lapitan MC, Omar MI, Lam TB, HilvanoCabungcal AM, Royle P, Stewart F, MacLennan G, MacLennan SJ, et al. Systematic review of perioperative and quality-of-life outcomes following surgical management of localised renal cancer. Eur Urol. 2012;62:1097-117.

5. Capitanio U, Montorsi F. Renal cancer. Lancet. 2016:387:894-906.

6. Wotschofsky Z, Liep J, Meyer HA, Jung M, Wagner I, Disch AC, Schaser KD, Melcher I, Kilic E, Busch J, et al. Identification of metastamirs as metastasis-associated microRNAs in clear cell renal cell carcinomas. Int J Biol Sci. 2012:8:1363-74

7. Tomaszewski JJ, Uzzo RG, Smaldone MC. Heterogeneity and renal mass biopsy: a review of its role and reliability. Cancer Biol Med. 2014:11:162-72.

8. Golovastova MO, Korolev DO, Tsoy LV, Varshavsky VA, Xu WH, Vinarov AZ, Zernii EY, Philippov PP, Zamyatnin AA Jr. Biomarkers of renal tumors: the current state and clinical perspectives. Curr Urol Rep. 2017;18:3.

9. Pastore AL, Palleschi G, Silvestri L, Moschese D, Ricci S, Petrozza V, Carbone A, Di Carlo A. Serum and urine biomarkers for human renal cell carcinoma. Dis Markers. 2015;2015:251403.

10. Schaefer A, Stephan C, Busch J, Yousef GM, Jung K. Diagnostic, prognostic and therapeutic implications of microRNAs in urologic tumors. Nat Rev Urol. 2010;7:286-97.

11. Gowrishankar B, Ibragimova I, Zhou Y, Slifker MJ, Devarajan K, Al-Saleem T, Uzzo RG, Cairns P. MicroRNA expression signatures of stage, grade, and progression in clear cell RCC. Cancer Biol Ther. 2014;15:329-41.

12. Chen X, Ba Y, Ma L, Cai X, Yin Y, Wang K, Guo J, Zhang Y, Chen J, Guo X, et al. Characterization of microRNAs in serum: a novel class of biomarkers for diagnosis of cancer and other diseases. Cell Res. 2008;18:997-1006.

13. Zen K, Zhang CY. Circulating microRNAs: a novel class of biomarkers to diagnose and monitor human cancers. Med Res Rev. 2012;32:326-48.

14. Wulfken LM, Moritz R, Ohlmann C, Holdenrieder S, Jung V, Becker F, Herrmann E, Walgenbach-Brunagel G, von Ruecker A, Muller SC, Ellinger J. MicroRNAs in renal cell carcinoma: diagnostic implications of serum miR1233 levels. PLoS One. 2011;6:e25787.

15. Zhai Q, Zhou L, Zhao C, Wan J, Yu Z, Guo X, Qin J, Chen J, Lu R. Identification of miR-508-3p and miR-509-3p that are associated with cell invasion and migration and involved in the apoptosis of renal cell carcinoma. Biochem Biophys Res Commun. 2012;419:621-6.

16. Redova M, Poprach A, Nekvindova J, lliev R, Radova L, Lakomy R, Svoboda M, Vyzula R, Slaby O. Circulating miR-378 and miR-451 in serum are potential biomarkers for renal cell carcinoma. J Transl Med. 2012;10:55.

17. Hauser S, Wulfken LM, Holdenrieder S, Moritz R, Ohlmann CH, Jung V, Becker F, Herrmann E, Walgenbach-Brunagel G, von Ruecker A, et al. Analysis of serum microRNAs (miR-26a-2*, miR-191, miR-337-3p and miR378) as potential biomarkers in renal cell carcinoma. Cancer Epidemiol. 2012:36:391-4.

18. Zhao A, Li G, Peoc'h M, Genin C, Gigante M. Serum miR-210 as a novel biomarker for molecular diagnosis of clear cell renal cell carcinoma. Exp Mol Pathol. 2013;94:115-20.

19. Iwamoto H, Kanda Y, Sejima T, Osaki M, Okada F, Takenaka A. Serum miR210 as a potential biomarker of early clear cell renal cell carcinoma. Int J Oncol. 2014;44:53-8

20. Fedorko M, Stanik M, lliev R, Redova-Lojova M, Machackova T, Svoboda M, Pacik D, Dolezel J, Slaby O. Combination of MiR-378 and MiR-210 serum levels enables sensitive detection of renal cell carcinoma. Int J Mol Sci. 2015, 16:23382-9

21. Heinemann FG, Tolkach Y, Deng M, Schmidt D, Perner S, Kristiansen G, Muller SC, Ellinger J. Serum miR-122-5p and miR-206 expression: non- 
invasive prognostic biomarkers for renal cell carcinoma. Clin Epigenetics. 2018;10:11.

22. Yadav S, Khandelwal M, Seth A, Saini AK, Dogra PN, Sharma A. Serum microRNA expression profiling: potential diagnostic implications of a panel of serum microRNAs for clear cell renal cell Cancer. Urology. 2017;104:64-9.

23. Tusong H, Maolakuerban N, Guan J, Rexiati M, Wang WG, Azhati B, Nuerrula Y, Wang YJ. Functional analysis of serum microRNAs miR-21 and miR-106a in renal cell carcinoma. Cancer Biomark. 2017;18:79-85.

24. Kurozumi A, Goto Y, Okato A, Ichikawa T, Seki N. Aberrantly expressed microRNAs in bladder cancer and renal cell carcinoma. J Hum Genet. 2017:62:49-56.

25. Yoshino $\mathrm{H}$, Enokida $\mathrm{H}$, Itesako T, Tatarano $\mathrm{S}$, Kinoshita T, Fuse M, Kojima $\mathrm{S}$, Nakagawa M, Seki N. Epithelial-mesenchymal transition-related microRNA200s regulate molecular targets and pathways in renal cell carcinoma. J Hum Genet. 2013;58:508-16.

26. Luo Y, Wang C, Chen X, Zhong T, Cai X, Chen S, Shi Y, Hu J, Guan X, Xia Z, et al. Increased serum and urinary microRNAs in children with idiopathic nephrotic syndrome. Clin Chem. 2013;59:658-66.

27. Wang C, Hu J, Lu M, Gu H, Zhou X, Chen X, Zen K, Zhang CY, Zhang T, Ge J, et al. A panel of five serum miRNAs as a potential diagnostic tool for earlystage renal cell carcinoma. Sci Rep. 2015;5:7610.

28. Chen X, Liang H, Guan D, Wang C, Hu X, Cui L, Chen S, Zhang C, Zhang J, Zen $\mathrm{K}$, Zhang CY. A combination of let-7d, let-7g and let-7i serves as a stable reference for normalization of serum microRNAs. PLoS One. 2013;8:e79652.

29. Wang C, Wu C, Yang Q, Ding M, Zhong J, Zhang CY, Ge J, Wang J, Zhang C. miR-28-5p acts as a tumor suppressor in renal cell carcinoma for multiple antitumor effects by targeting RAP1B. Oncotarget. 2016;7:73888-902.

30. Pan Y, Liang H, Chen W, Zhang H, Wang N, Wang F, Zhang S, Liu Y, Zhao C, Yan X, et al. microRNA-200b and microRNA-200c promote colorectal cancer cell proliferation via targeting the reversion-inducing cysteine-rich protein with Kazal motifs. RNA Biol. 2015;12:276-89.

31. Ding $M$, Sun $X$, Zhong J, Zhang C, Tian Y, Ge J, Zhang CY, Zen K, Wang JJ, Zhang C, Wang C. Decreased miR-200a-3p is a key regulator of renal carcinoma growth and migration by directly targeting CBL. J Cell Biochem. 2018;119(12):9974-85.

32. Wu L, Timmers C, Maiti B, Saavedra HI, Sang L, Chong GT, Nuckolls F, Giangrande P, Wright FA, Field SJ, et al. The E2F1-3 transcription factors are essential for cellular proliferation. Nature. 2001;414:457-62.

33. Liu H, Tang X, Srivastava A, Pecot T, Daniel P, Hemmelgarn B, Reyes S, Fackler N, Bajwa A, Kladney R, et al. Redeployment of Myc and E2f1-3 drives Rb-deficient cell cycles. Nat Cell Biol. 2015;17:1036-48.

34. Chan YC, Banerjee J, Choi SY, Sen CK. miR-210: the master hypoxamir. Microcirculation. 2012;19:215-23.

35. Zhou L, Li Z, Pan X, Lai Y, Quan J, Zhao L, Xu J, Xu W, Guan X, Li H, et al. Identification of miR-18a-5p as an oncogene and prognostic biomarker in RCC. Am J Transl Res. 2018;10:1874-86.

36. Kent LN, Bae S, Tsai SY, Tang X, Srivastava A, Koivisto C, Martin CK, Ridolfi E, Miller GC, Zorko SM, et al. Dosage-dependent copy number gains in E2f1 and E2f3 drive hepatocellular carcinoma. J Clin Invest. 2017;127:830-42.

37. Liang B, Zhao J, Wang X. Clinical performance of E2Fs 1-3 in kidney clear cell renal cancer, evidence from bioinformatics analysis. Genes Cancer. 2017:8:600-7.

38. Gao Y, Li H, Ma X, Fan Y, Ni D, Zhang Y, Huang Q, Liu K, Li X, Wang L, et al. E2F3 upregulation promotes tumor malignancy through the transcriptional activation of HIF-2alpha in clear cell renal cell carcinoma. Oncotarget. 2017; 8:54021-36.

39. Gao Y, Feng B, Lu L, Han S, Chu X, Chen L, Wang R. MiRNAs and E2F3: a complex network of reciprocal regulations in human cancers. Oncotarget. 2017:8:60624-39

40. Luo T, Chen X, Zeng S, Guan B, Hu B, Meng Y, Liu F, Wong T, Lu Y, Yun C, et al. Bioinformatic identification of key genes and analysis of prognostic values in clear cell renal cell carcinoma. Oncol Lett. 2018;16:1747-57.

41. Chen $X$, Liang $H$, Zhang J, Zen $K$, Zhang CY. Secreted microRNAs: a new form of intercellular communication. Trends Cell Biol. 2012;22:125-32.

42. Li J, Zhang Y, Liu Y, Dai X, Li W, Cai X, Yin Y, Wang Q, Xue Y, Wang C, et al. Microvesicle-mediated transfer of microRNA-150 from monocytes to endothelial cells promotes angiogenesis. J Biol Chem. 2013;288:23586-96.

43. Yin Y, Cai X, Chen X, Liang H, Zhang Y, Li J, Wang Z, Chen X, Zhang W, Yokoyama $S$, et al. Tumor-secreted miR-214 induces regulatory $T$ cells: a major link between immune evasion and tumor growth. Cell Res. 2014;24:1164-80.
44. Zhang W, Ni M, Su Y, Wang H, Zhu S, Zhao A, Li G.MicroRNAs in serum exosomes as potential biomarkers in clear-cell renal cell carcinoma.Eur Urol Focus. 2018:4(3):412-19.

45. Qu L, Ding J, Chen C, Wu ZJ, Liu B, Gao Y, Chen W, Liu F, Sun W, Li XF, et al. Exosome-transmitted IncARSR promotes Sunitinib resistance in renal Cancer by acting as a competing endogenous RNA. Cancer Cell. 2016;29:653-68.
Ready to submit your research? Choose BMC and benefit from:

- fast, convenient online submission

- thorough peer review by experienced researchers in your field

- rapid publication on acceptance

- support for research data, including large and complex data types

- gold Open Access which fosters wider collaboration and increased citations

- maximum visibility for your research: over $100 \mathrm{M}$ website views per year

At BMC, research is always in progress.

Learn more biomedcentral.com/submissions 